\title{
Influence of pre- and post-copulatory pair contact on pregnancy success in Djungarian hamsters, Phodopus campbelli
}

\author{
K. E. Wynne-Edwards, U. W. Huck* and R. D. Lisk \\ Department of Biology, Princeton University, Princeton, NJ 08544, U.S.A.
}

\begin{abstract}
Summary. Females housed with their mates for 3 or 4 days before mating took place (i.e. early in the oestrous cycle at the time of introduction to the mate) were significantly more likely to litter than were females housed with their mates for only 1 or 2 days before mating. The duration of post-copulatory pair contact had a complex effect on pregnancy success. While only $41 \%$ of females littered when they had $24 \mathrm{~h}$ of post-copulatory pair contact, females exposed to either longer or shorter durations of post-copulatory pair contact littered at significantly higher rates. Exposure to a strange male $2448 \mathrm{~h}$ after mating did not produce a strange-male induced pregnancy block. The critical parameter responsible for the decrease in the number of females littering was the absence of the mate, irrespective of the presence or absence of a strange male. If this pattern of pregnancy block is adaptive for females, it seems probable that females in the wild require substantial levels of paternal investment by their mates.
\end{abstract}

\section{Introduction}

The presence or absence of conspecifics can provide a female with information about the probability of an attempt at reproduction being successful. This is especially true in species with social systems that provide the potential for either (a) increased reproductive success through parental investment by conspecific adults other than the mother or (b) decreased reproductive success through infanticide. Thus, under some social conditions, it might be adaptive for a female to adjust her investment in a particular reproductive attempt. Females which could accurately (1) identify social environments likely to result in low survivorship for her offspring and (2) respond by terminating further investment, would conserve both energy and time. The result would be a potential increase in her lifetime reproductive success. There is a growing body of evidence suggesting that small mammals are capable of these adaptive responses. The presence or absence of other conspecifics affects individual reproductive physiology in several ways. These include oestrous synchrony in females (McClintock, 1983), acceleration or delay of sexual maturation (Drickamer, 1979; Terman, 1980; Vandenbergh, 1983), post-copulatory pregnancy block (Bruce, 1959; Schwagmeyer, 1979; Labov, 1981; Marchlewska Koj, 1983), peri-copulatory pregnancy block (Dewsbury, 1982; Wynne-Edwards \& Lisk, 1984) and pregnancy maintenance (Richmond \& Stehn, 1976; Berger \& Negus, 1982; Storey, 1986).

Djungarian hamsters (Phodopus campbelli) show a peri-copulatory pregnancy block. Females mate and ovulate but fail to initiate progestation when they are housed with two fertile males (Wynne-Edwards \& Lisk, 1984). The present study was designed to extend these observations of a strong peri-copulatory pregnancy block to a study of the influence of pair contact on pregnancy success in Djungarian hamsters. The results are organized as three experiments to study the effect

*Present address: Biology Program, Sangamon State University, Springfield, IL 62708, U.S.A. 
on pregnancy success of: (1) increasing the duration of precopulatory pair contact, (2) increasing the duration of post-copulatory pair contact and (3) the presence of a strange male $24-48 \mathrm{~h}$ after mating.

\section{General Methods}

The Djungarian hamsters were descendents of animals captured in Tuva, Siberia, in 1965 and maintained at Princeton since 1981. During that interval the animals have been maintained in Rumania, the United Kingdom and the United States. The Princeton colony was started in 1981 with animals obtained from Dr Michael R. Murphy of the National Institute of Mental Health. In 1984 it was outbred against wild-caught stock obtained from Dr A. B. Surov of the Institute of Evolutionary Morphology and Animal Ecology of the Academy of Sciences of the U.S.S.R. while the senior author was conducting field studies on the Siberian hamster (Phodopus sungorus). The Djungarian hamster (Phodopus campbelli) has been considered to be conspecific with the Siberian hamster (Phodopus sungorus) (Vorontsov et al., 1967, Kartavtsev et al., 1984), which is extensively used in laboratories to study the endocrine basis of the photoperiodic response (e.g. Yellon \& Goldman, 1984; Wade \& Bartness, 1984; Duncan et al., 1985; Hoffman \& Illnerova, 1986). However, the two species are not sympatric (Flint, 1966), produce infertile hybrid offspring (Iudin et al., 1979) and differ in their copulatory patterns and levels of social interaction with conspecifics (K. E. WynneEdwards, unpublished).

Females were all virgins between 90 and 120 days of age at the beginning of the experiment. Each was housed alone for at least 14 days before testing. Males were proven breeders (120-200 days old) rested for at least 14 days. Experiments were conducted in individual $35 \mathrm{~cm} \times 20 \mathrm{~cm}$ cages provided with wood shavings, food and water. Both the experimental room and the colony room were maintained on a $14 \mathrm{~h}$ light:10 h dark photoperiod with lights off at 19:00 h. All females were allowed $24 \mathrm{~h}$ to acclimatize to the cage before the introduction of the mate. Following the experiment each female was placed alone in a clean cage and left undisturbed until parturition.

The majority of Djungarian hamster females display regular, 4-day, behavioural oestrous cycles (Wynne-Edwards \& Lisk, 1984). About $15 \%$ of females show at least occasional 5-day behavioural cycles. Djungarian hamsters are spontaneous ovulators as determined by the presence of oviducal eggs about $6-10 \mathrm{~h}$ after the onset of behavioural oestrus in the unmated female (Wynne-Edwards et al., 1987). In spite of considerable effort in our laboratory it has proved impossible to monitor the oestrous cycles of females through vaginal smears. Although there are changes in the vaginal cytology, no 4 day pattern emerges. Oestrous cycles can therefore only be monitored through brief daily interactions with breeding males. The studies reported here were directly concerned with the interaction between contact with males and pregnancy success and so females were not given any prior exposure to males and the stage of each female's oestrous cycle was unknown at the beginning of each experiment.

The copulatory pattern of the Djungarian hamster consists of multiple ejaculatory series, each of which is composed of multiple intromissions (unpublished data: Sawrey et al., 1985). Mating in pairs housed together is entrained to the light cycle and begins during an interval extending from $1 \mathrm{~h}$ before lights out to $1 \mathrm{~h}$ after lights out. During the first hour of mating there is a highly stereotyped male copulatory pattern consisting of 3-5 ejaculatory series, an ejaculatory lock of 7-9 sec and an 8-15 min post-ejaculatory quiescent period. After the first hour of mating there is considerable variance across fertile males in their copulatory pattern. Some males cease mounting, some males commence brief ejaculatory series with or without intromissions and having very short ejaculatory locks $(1-3 \mathrm{sec})$ and some males continue to mount without intromissions. The length of time that the mounting behaviour persists is also variable across males but generally does not exceed $3 \mathrm{~h}$ (Wynne-Edwards \& Lisk, 1984). Based upon this information, a period of $2 \mathrm{~h}$ from the first observed mount was chosen as an appropriate interval to separate copulatory from post-copulatory behaviour.

\section{Detailed Methods and Results}

\section{Experiment 1}

This consisted of an analysis of breeding records to determine whether there was a connection between the amount of pre-copulatory contact with the mate and the probability that a female would deliver a litter.

Procedure. Over a period of 4 years several different experiments were conducted using the same pre-copulatory paradigm which introduced males and females without prior knowledge of the stage of the female's oestrous cycle. Since the oestrous cycle is usually 4 days in length, behavioural oestrus could occur on the day of introduction or one of the three subsequent days. For a total of 330 females it was possible to compare the number of days between the introduction of the mate and mating (determined by direct observation of at least one ejaculation) and the proportion of females that successfully delivered litters. A small number $(<15)$ of females mated on the 5 th day 
after introduction. The majority of these females were probably showing a 5-day oestrous cycle. Nevertheless, they were excluded from the analysis because of the slight possibility that they were on a 4-day cycle and the observer had failed to detect previous copulatory behaviour on the day of introduction.

Statistics. A $\chi^{2}$ analysis with four independent samples (for the four possible precopulatory intervals) was conducted on the data. Pairwise $\chi^{2}$ analyses were used to identify significant differences between groups. In all cases $P \leqslant 0.05$ was required for significance.

Results. As shown in Table 1, several significant results were obtained. The probability that a female would deliver a litter was significantly affected by the duration of pre-copulatory contact $\left(\chi^{2}=14.2, P \leqslant 0.01\right)$. The probability that a female would deliver a litter did not differ significantly for 1 or 2 days of pre-copulatory contact or for 3 or 4 days of pre-copulatory contact, but females were significantly more likely to deliver litters after 3 or 4 days of pre-copulatory contact than after just 1 or 2 days. An equal number of females did not become receptive on each of the 4 possible days $\left(\chi^{2}=7 \cdot 7, P \leqslant 0 \cdot 01\right)$.

Table 1. The percentage of females successfully littering after different lengths of precopulatory contact with the mate (Exp. 1)

\begin{tabular}{lcc}
\hline $\begin{array}{l}\text { Duration of precopulatory } \\
\text { contact with the mate } \\
\text { (days) }\end{array}$ & $\begin{array}{c}\text { Sample } \\
\text { size }\end{array}$ & $\begin{array}{c}\text { Females } \\
\text { littering } \\
(\%)\end{array}$ \\
\hline 1 & 100 & $48^{\mathrm{a}}$ \\
2 & 66 & $45^{\mathrm{a}}$ \\
3 & 87 & $64^{\mathrm{b}}$ \\
4 & 77 & $69^{\mathrm{b}}$ \\
\hline
\end{tabular}

Values with different superscripts are significantly different, $P<0.05$.

\section{Experiment 2}

This was designed to investigate the effect of post-copulatory contact with the mate on the probability that a female would successfully deliver a litter.

Procedure. Six experimental groups were tested (see Table 2). In the first group (Group 1) the males were introduced to the female's cage for $30 \mathrm{~min}$ daily until mating was observed. Males then remained with the female for $2 \mathrm{~h}$ during which mating occurred. After $48 \mathrm{~h}$ the female was placed in a clean cage. In Groups 2-4 the female remained in continuous contact with the mate from introduction through mating. They differed from each other only in the length of post-copulatory contact, receiving no post-copulatory contact (i.e. males were separated from females $2 \mathrm{~h}$ after the first mount) (Group 2), or $24 \mathrm{~h}$ (Group 3) or $48 \mathrm{~h}$ (Group 4) of post-copulatory contact. In all cases the female remained in her familiar cage until $48 \mathrm{~h}$ after mating before being placed in a clean cage. In Group 5 pairs were housed together for 5 days, irrespective of the day on which mating was observed, and so a pair could have from 24 to $96 \mathrm{~h}$ of post-copulatory contact. In Group 6, females remained with the males in small boxes throughout gestation. All females that showed visible signs of pregnancy delivered litters.

Statistics. All females were scored as (1) littering successfully or (2) failed to litter. $\chi^{2}$ tests were used to determine overall significance within the experiment and the sources of significant variation between experimental groups by pairwise comparison of all groups. In all cases, $P \leqslant 0.05$ was required for significance. 
Results. As shown in Table 2, the duration of post-copulatory contact with the mate strongly influenced the probability of a female delivering a litter $\left(\chi^{2}{ }_{5}=20.02 ; P \leqslant 0.002\right)$. Increasing contact from the minimum tested (Group 1) to $24 \mathrm{~h}$ of post-copulatory contact (Group 3 ) significantly decreased the number of females littering successfully $\left(\chi^{2}{ }_{1}=7 \cdot 66 ; P \leqslant 0.006\right)$. Further increasing the duration of post-copulatory contact from $24 \mathrm{~h}$ (Group 3 ) to just $48 \mathrm{~h}$ (Group 4 ) reversed the trend and significantly increased the number of females littering $\left(\chi_{1}^{2}=5 \cdot 26 ; P \leqslant 0.03\right)$. Pregnancy success continued to increase as the duration of post-copulatory contact with the mate increased. All experimental groups except Group $2\left(\chi^{2}{ }_{1}=2 \cdot 19 ; P=0 \cdot 14\right)$ had significantly higher pregnancy success rates than did Group 3 ( $24 \mathrm{~h}$ of contact).

Table 2. The percentage of females successfully littering after various durations of postcopulatory contact with the mate (Exp. 2)

\begin{tabular}{lccc}
\hline Group & $\begin{array}{c}\text { Duration of } \\
\text { postcopulatory } \\
\text { contact }\end{array}$ & $\begin{array}{c}\text { Sample } \\
\text { size }\end{array}$ & $\begin{array}{c}\text { Females } \\
\text { littering } \\
(\%)\end{array}$ \\
\hline 1 & None & 22 & 91 \\
2 & None & 20 & 75 \\
3 & $24 \mathrm{~h}$ & 42 & $41^{*}$ \\
4 & $48 \mathrm{~h}$ & 41 & 81 \\
5 & $\leqslant 96 \mathrm{~h}$ & 20 & 95 \\
6 & 18 days & 12 & 92 \\
\hline
\end{tabular}

*Significantly different from that of all other groups except Group $2(P<0.05)$.

\section{Experiment 3}

This was designed to determine whether Djungarian hamsters were susceptible to the pregnancy blocking effect of a strange male. Two experimental paradigms were tested. In the first the female remained in direct contact with the stimulus animal. In the second the stimulus animal was confined to a small enclosure within the female's cage.

Procedure. Females were assigned to one of 6 experimental groups then mated using the same procedure as in Exps 1 and 2. For the three 'contact' groups both the male and female were handled briefly $24 \mathrm{~h}$ after mating and then the female remained a further $24 \mathrm{~h}$ with the mate (Group $7 \mathrm{~A} \equiv$ Group 4 in Exp 2), a rested, strange adult male (Group 8A) or no other animal (Group $9 \mathrm{~A} \equiv$ Group 3 in Exp. 2). For the 'limited contact' groups the protocol was the same except that the arena contained a $5 \times 5 \times 8 \mathrm{~cm}$ enclosure constructed of hardware cloth (Groups 7B, 8B \& 9B). During the experimental interval from 24 to $48 \mathrm{~h}$ after mating, the stimulus animal was confined in the enclosure rather than freely interacting with the mated female. At $48 \mathrm{~h}$ after mating each female was placed alone in a clean cage and left undisturbed until parturition. All females that became visibly pregnant delivered litters successfully.

Statistics. Again, all females were scored as (1) littering successfully or (2) failed to litter, for each experimental condition. $\chi^{2}$ tests were used to determine overall significance within the experiment. The high pregnancy rate seen in females remaining in contact with the mate for a full $48 \mathrm{~h}$ after mating (Group 7A) was used as the control group. All other experimental groups were compared to it to identify significant sources of variation. In all cases $P \leqslant 0.05$ was required for significance.

Results. As shown in Table 3, the overall experiment showed a significant effect $\left(\chi^{2}{ }_{5}=18 \cdot 12\right.$; $P \leqslant 0 \cdot 005$ ). All of the experimental groups differed significantly from the control group (Group 
7A) $(P \leqslant 0.02)$. However, none of the remaining 5 groups (Groups 7B, 8A, 8B, 9A \& 9B) differed significantly from each other $(P \geq 0.15$ for each pairwise comparison). Limiting the contact with the mate to that possible through the enclosure produced a significant pregnancy block (Group 7B: $\chi^{2}{ }_{1}=6.66 ; P \leqslant 0.01$ ) not different from the level found when the female was housed alone (Group 9A). The effect of the strange male did not depend upon contact because Groups $8 \mathrm{~A}$ and $8 \mathrm{~B}$ did not differ significantly $\left(\chi_{1}^{2}{ }_{1}=2 \cdot 06 ; P=0 \cdot 15\right)$. The enclosure per se did not affect the pregnancy rate as there was no significant difference between Groups $9 \mathrm{~A}$ and $9 \mathrm{~B}\left(\chi_{1}{ }_{1}=0.41 ; P=0.52\right)$.

Table 3. The percentage of females successfully littering in Exp. 3 when females were exposed to different experimental conditions $24-48 \mathrm{~h}$ after mating

\begin{tabular}{llcc}
\hline Group* & $\begin{array}{c}\text { Stimulus } \\
\text { animal }\end{array}$ & $\begin{array}{c}\text { Sample } \\
\text { size }\end{array}$ & $\begin{array}{c}\text { Females } \\
\text { littering } \\
(\%)\end{array}$ \\
\hline 7A & Mate & 41 & 81 \\
7B & Mate & 54 & $57 \dagger$ \\
8A & Strange male & 42 & $41 \dagger$ \\
8B & Strange male & 39 & $56 \dagger$ \\
9A & None & 42 & $57 \dagger$ \\
9B & None & 38 & $50 \dagger$ \\
\hline
\end{tabular}

*Groups designated A remained in direct contact with the stimulus animal. Groups designated B had the stimulus animal confined inside a wire-mesh enclosure within the arena.

+ Values significantly different $(P<0.05)$ from that of Group 7A but not from each other.

\section{Discussion}

Pre-copulatory pair contact, post-copulatory pair contact and the presence of the mate all had significant effects on pregnancy success. Females housed with their mates for 3 or 4 days before mating took place (i.e. early in their oestrous cycles at the time of introduction to the mate) were significantly more likely to deliver litters than females housed with their mates for only 1 or 2 days before mating. The duration of post-copulatory pair contact had a complex effect on pregnancy success. While only $41 \%$ of females delivered litters when they had $24 \mathrm{~h}$ of post-copulatory pair contact, females exposed to longer or shorter post-copulatory pair contact littered at significantly higher rates which were not different from each other. The data from exposure to a strange male $2448 \mathrm{~h}$ after mating indicate that the critical factor responsible for the decrease in the number of females littering was the absence of the mate, irrespective of the presence or absence of a strange male.

Significantly more females delivered litters when the length of pre-copulatory pair contact exceeded 2 days. Perhaps increasing familiarity with the mate decreased some of the stressful effects associated with encountering a stranger which could adversely affect the reproductive physiology of pregnancy initiation (Kittenger et al., 1980; Rivier et al., 1986). Since Djungarian hamsters are spontaneous ovulators this would occur if they were early in their oestrous cycles when they were introduced to their mates or if they had previous social experience with the mate.

An equal number of females did not mate on each of the 4 possible days as would be expected for females taken at random from a pool showing 4-day oestrous cycles. Females were, however, 
evenly distributed as early (the first 2 days) or late (the last 2 days) matings. The pattern of the distribution, with an excess of Day 1 matings and a dearth of Day 2 matings, was retained in several sub-samples analysed from populations of females tested in different seasons and different years. If induction of oestrus were occurring we would predict a surplus of females mating on the 3rd or 4th day after introduction (McClintock, 1983). Since females that mate on the first day do so within $30 \mathrm{~min}$ of introduction, exposure to the mate is unlikely to be responsible for the relatively large number of females that mate immediately. It is possible that some element of the prior $24 \mathrm{~h}$ acclimatization period shortened 5-day cycles to 4-day cycles in females in a sensitive period of dioestrus. Alternatively, there may be another physiological mechanism responsible which is currently unknown.

Pregnancy block occurred in females in response to the removal of the mate $24 \mathrm{~h}$ after mating compared to the high percentage of females that littered when the duration of post-copulatory pair contact was longer or shorter than $24 \mathrm{~h}$. It is possible that, because only $24 \mathrm{~h}$ durations showed significant levels of pregnancy block, the block is an artefactual response which is only manifested during that critical period. However, the pattern of pregnancy success appears to be a graded response with decreasing rates as contact increased through $24 \mathrm{~h}$ and then increasing pregnancy rates as contact continued to increase. Some parameters essential to the interpretation of these data are amenable to experimental verification. If $24 \mathrm{~h}$ is a critical physiological period sensitive to pregnancy block then the same pattern should be found in females of different ages and different reproductive histories. However, if the removal of the mate is functioning as a signal to the female that it would be adaptive to terminate further investment in her litter, then we should be able to demonstrate that females which are younger (and have more future potential to reproduce) are more likely to show a pregnancy block than older females which are still virgins and have fewer remaining reproductive opportunities. The virgin females used in this study were at least 3 months old and had not had any contact with males since weaning. Djungarian hamster females are capable of a fertile mating as early as 32 days of age (K. E. Wynne-Edwards, unpublished). It is possible that, because of the long time during which they had been cycling without access to a mate, they showed a lower incidence of pregnancy block than a younger population of virgin females might have shown.

The high pregnancy success of females that received no post-copulatory pair contact may also be explicable in terms of the future potential of those females to reproduce. All arguments about the adaptive nature of a pregnancy block in response to desertion by the mate conclude that a parent should only terminate investment in a current reproductive attempt when the probability of successfully raising those offspring to weaning is so low that selection favours rapid re-investment in another reproductive attempt (Trivers, 1972; Dawkins \& Carlisle, 1976). This requires that females which continue to invest in a litter after they are deserted by their mates should, on average, be significantly less successful than their paired counterparts at raising their young to weaning. A test of this prediction is currently in preparation.

Although the strange-male induced pregnancy block in recently inseminated mice (Bruce, 1959) has since been described for a wide variety of small mammals (see Labov, 1981) it does not occur in all species. The rat (Davis \& DeGroot, 1969) and the gerbil (Norris \& Adams, 1979) do not show a typical pregnancy block. The present study indicates that strange-male induced pregnancy block does not occur in Djungarian hamsters although fewer females litter when their mate is removed or confined. These data would have been consistent with the presence of strange-male induced pregnancy block if the control groups in which the female was housed alone (Groups 9A \& 9B) had not been included in the design. Norris (1985) reached the same conclusion to explain the incidence of pregnancy block in Mongolian gerbils. Out of a literature containing considerable confusion about the incidence and causes of pregnancy block in gerbils (Norris \& Adams, 1979; Rohrbach, 1982), Norris (1985) constructed another study which controlled for the effect of removing the stud male and concluded that the exteroceptive factor responsible for pregnancy block in Mongolian gerbils was the disruption of the pair. It is possible that more of the reported cases of strange-male induced 
pregnancy block in the literature could be reinterpreted as responses to the removal of the mate. Such a literature already exists, investigating the social factors involved in the maintenance of successful pregnancy in reflex ovulators: the presence of the mate for an extended time after mating has been demonstrated to have a significant, positive effect on the number of females which will successfully litter in field voles (Microtus ochrogaster; Richmond \& Stehn, 1976), montane voles ( $M$. montanus; Berger \& Negus, 1982), meadow voles (M. pennsylvanicus; Storey, 1986) and redbacked voles (Clethrionomys gapperi; Clulow et al., 1982).

Across species there are differences in the cues necessary to elicit strange-male induced pregnancy block (Terman, 1969; Milligan, 1976) and extensive discussions of the adaptiveness of the phenomenon from both the positive (Mallory \& Clulow, 1977; Hrdy, 1979; Heske \& Nelson, 1984; Huck, 1984) and the negative viewpoints (Bronson \& Coquelin, 1980). On the positive side, several possible adaptive reasons for this pregnancy blocking effect have been suggested (Schwagmeyer, 1979), particularly infanticidal behaviour of the strange male towards offspring sired by the original male (reviewed in Huck, 1984). The peri-copulatory pregnancy block in females mating with several males in Djungarian hamsters, Phodopus campbelli (Wynne-Edwards \& Lisk, 1984) and deermice, Peromyscus maniculatus (Dewsbury, 1982) may have a similar mechanism (Dewsbury, 1985) and a similar adaptive basis. The negative impact on survival of young that could result from decreased certainty of paternity associated with promiscuous mating was proposed as a selective pressure for the evolution of pregnancy block (Dewsbury, 1982; Wynne-Edwards \& Lisk, 1984). Mallory \& Clulow (1977) found several generations of corpora lutea in the ovaries of female voles trapped from the wild. The ovaries were morphologically similar to those of females sequentially exposed to the pregnancy blocking effect of strange males and they argued that pregnancy disruption was common in the wild. Heske \& Nelson (1984) compared the ability of strange males to block pregnancy in standard, small, test arenas and in larger, complex habitats. In spite of the potential for escape by the female, aggression towards the intruder male, or beneficial effects on the continued presence of the mate, pregnancy block still occurred in the complex habitats. On the negative side, none of the peri-copulatory (Dewsbury, 1985), the post-copulatory (Bruce \& Parkes 1961; Mallory \& Clulow, 1977; Rohrbach, 1982), or the pair-disruption (Norris, 1985) pregnancy blocks occur in females mated at a post-partum oestrus, possibly as a result of the high prolactin levels associated with lactation (Bronson et al., 1969; Marchlewska-Koj, 1983). If the majority of matings in the field occur at post-partum oestrus, and the pregnancy block is adaptive, pregnancy block should also occur after post-partum matings.

The social context in which pregnancy block occurs, if it is adaptive, must depend on the natural social organization of each species. When we first described a peri-copulatory pregnancy block in Djungarian hamsters (Wynne-Edwards \& Lisk, 1984) we were left with two possible explanations. It could be an artefact of a physiological mechanism with a different function in regulating reproduction (Bronson, 1985) or it could be adaptive. If it was adaptive then two major hypotheses were present in the literature. Either paternal investment was important to the female and she would terminate further investment in the pregnancy if she were deserted by her mate after mating (Dawkins \& Carlisle, 1976; Zeveloff \& Boyce, 1980) or, if the potential for infanticide by an unrelated male was the driving factor behind the evolution of this pregnancy block, females should be relatively unaffected by the removal of their mate but should show a strange-male induced pregnancy block with exposure during the first few days after mating (Huck, 1984). The three experiments reported in this study suggest that Djungarian hamster females are very sensitive to the continued presence of their mate and pregnancies tend to fail when they are deserted by him. The Djungarian hamster is part of a palaearctic radiation of 5 genera of dwarf hamsters. Native to the steppes of central Siberia, Mongolia and North China, little is known about the natural mating system (Flint, 1966). Based on the pattern of pregnancy block described here seems reasonable to predict that significant paternal investment in her litter is important for female reproductive success in the wild.

While it is still not clear whether pregnancy blocking phenomena occur in natural populations it 
is becoming abundantly clear that exteroceptive social factors are capable of affecting reproductive physiology and pregnancy success in a multitude of ways. If the information provided to a female is an accurate predictor of the probable success of a reproductive attempt, it would be adaptive for her to respond to that stimulation with a pregnancy block provided she could compensate for her energetic loss through subsequent successful reproduction.

This research was conducted while the senior author held a Princeton University Graduate Fellowship.

\section{References}

Berger, P.J. \& Negus, N.C. (1982) Stud male maintenance of pregnancy in Microtus montanus. J. Mamm. 63, 148-151.

Bronson, F.H. (1985) Mammalian reproduction: an ecological perspective. Biol. Reprod. 32, 1-26.

Bronson, F.H. \& Coquelin, A. (1980) The modulation of reproduction by priming pheromones in house mice: speculations on adaptive function. In Chemical Signals. Vertebrates and Aquatic Invertebrates, pp. 243-265. Eds D. Muller-Schwartze \& R. M. Silverstein. Plenum Press, New York.

Bronson, F.H., Eleftheriou, B.E. \& Dezell, H.E. (1969) Strange male pregnancy block in deermice: prolactin and adrenocortical hormones. Biol. Reprod. 1, 302-306.

Bruce, H.M. (1959) An exteroceptive block to pregnancy in the mouse. Nature, Lond. 184, 105.

Bruce, H.M. \& Parkes, A.S. (1961) The effect of concurrent lactation on the olfactory block to pregnancy in the mouse. J. Endocr. 22, 6-7.

Clulow, F.V., Franchetto, E.A. \& Langford, P.E. (1982) Pregnancy failure in the red-backed vole, Clethrionomys gapperi. J. Mamm. 63, 499-500.

Davis, D.L. \& DeGroot, J. (1969) Failure to demonstrate olfactory inhibition of pregnancy ('Bruce Effect') in the rat. Anat. Rec. 148, 366-369.

Dawkins, R. \& Carlisle, T.R. (1976) Parental investment, mate desertion and a fallacy. Nature, Lond. 262, 131-133.

Dewsbury, D.A. (1982) Pregnancy blockage following multiple-male copulation or exposure at the time of mating in deer mice, Peromyscus maniculatus. Behav. Ecol. Sociobiol. 11, 37-42.

Dewsbury, D.A. (1985) Studies of pericopulatory pregnancy blockage and the gestation period in deer mice (Peromyscus maniculatus). Horm. Behav. 19, 164-173.

Drickamer, L.C. (1979) Acceleration and delay of first estrus in wild Mus musculus. J. Mamm. 60, 215-216.

Duncan, M.J., Goldman, B.D., DiPinto, M.N. \& Stetson, M.H. (1985) Testicular function and pelage color have different critical daylengths in the Djungarian hamster Phodopus sungorus sungorus. Endocrinology 116, 424-430.

Flint, W.E. (1966) Die Zwerghamster der Palaarktischen Fauna, 99 pp. Zeimson-Verlag, Wittenberg.

Heske, E.J. \& Nelson, R.J. (1984) Pregnancy interruption in Microtus ochrogaster: laboratory artifact or field phenomenon? Biol. Reprod. 31, 97-103.
Hoffman, K. \& Illnerova, H. (1986) Photoperiodic effects in the Djungarian hamster. Neuroendocrinology 43, 317-321.

Hrdy, S. (1979) Infanticide among animals: a review, classification and examination of the implications for the reproductive strategies of females. Ethol. Sociobiol. 1, 13-40.

Huck, U.W. (1984) Infanticide and the evolution of pregnancy block in rodents. in Infanticide: Comparative and Evolutionary Perspectives, pp. 349-365. Eds G. Hausfater \& S. B. Hrdy. Aldine, New York.

Iudin, B.C., Galkina, L.I. \& Potapkina, A.F. (1979) [Mammals of the Altai-Sayanskoi Gornoi district], pp. 152-158 Nauka, Novosibirsk. [In Russian.]

Kartavtsev, Y.F., Kartavtseva, I.V. \& Vorontsov, N.N. (1984) Population genetics and genogeography of wild mammals. IV Level of heterozygosity in five species of palearctic hamsters. Genetika 20, 954960 .

Kittenger, J.W., Gutierrez-Cernosek, R.M., Cernosek, S.F. \& Pasley, T.N. (1980) Effects of adrenocorticotropin on pregnancy and prolactin in mice. Endocrinology 107, 616-621.

Labov, J.B. (1981) Pregnancy blocking in rodents; adaptive advantages for females. Am. Nat. 118, 361-371.

Mallory, F.F. \& Clulow, F.V. (1977) Evidence of pregnancy failure in the wild meadow vole, Microtus pennsylvanicus. Can. J. Zool. 55, 1-17.

Marchlewska-Koj, A. (1983) Pregnancy blocking by pheromones. In Pheromones and Reproduction in Mammals, pp. 151-174. Ed. J. G. Vandenbergh. Academic Press, New York.

McClintock, M.K. (1983) Pheromonal regulation of the ovarian cycle: enhancement, suppression, and synchrony. In Pheromones and Reproduction in Mammals, pp. 113-149. Ed. J. G. Vandenbergh. Academic Press, New York.

Milligan, S.R. (1976) Pregnancy blocking in the vole, Microtus agrestis. I. Effect of the social environment. J. Reprod. Fert. 46, 91-95.

Norris, M.L. (1985) Disruption of pair bonding induces pregnancy failure in newly mated Mongolian gerbils (Meriones unguiculatus). J. Reprod. Fert. 75, 43-47.

Norris, M.L. \& Adams, C.E. (1979) Exteroceptive factors and pregnancy block in the Mongolian gerbil, Meriones unguiculatus. J. Reprod. Fert. 57, 401-404.

Richmond, M. \& Stehn, R. (1976) Olfaction and reproductive behaviour in the microtine rodents. In Mammalian Olfaction, Reproductive Processes, and 
Behavior, pp. 197-217. Ed. R. L. Doty. Academic Press, New York.

Rivier, C., Rivier, J. \& Vale, W. (1986) Stress-induced inhibition of reproductive functions: role of endogenous corticotropin-releasing factor. Science, N.Y. 231, 607-609.

Rohrbach, C. (1982) Investigation of the Bruce effect in the Mongolian gerbil (Meriones unguiculatus). $J$. Reprod. Fert. 65, 411-417.

Sawrey, D.K., Baumgardner, D.J., Campa, M.J., Ferguson, B., Hodges, A.W. \& Dewsbury, D.A. (1984) Behavioral patterns of Djungarian hamsters: an adaptive profile. Anim. Learn. Behav. 12, 297-306.

Schwagmeyer, P.L. (1979) The Bruce Effect: an evaluation of male/female advantages. Am. Nat. 114, 932-938.

Storey, A.E. (1986) Influence of sires on male-induced pregnancy disruptions in meadow voles (Microtus pennsylvanicus) differs with stage of pregnancy. $J$. comp. Psych. 100, 15-20.

Terman, C.R. (1969) Pregnancy failure in deermice related to parity and social environment. Anim. Behav. 17, 104-108.

Terman, C.R. (1980) Social factors influencing delayed reproductive maturation in prairie deermice (Peromyscus maniculatus bairdii) in laboratory populations. J. Mamm. 61, 219-223.

Trivers, R.L. (1972) Parental investment and sexual selection. In Sexual Selection and the Descent of Man 1871-1971, pp. 136-179. Ed. B. Campbell. AldineAtherton, Chicago.
Vandenbergh, J.G. (1983) Pheromonal regulation of puberty. In Pheromones and Reproduction in Mammals, pp. 95-112. Ed. J. G. Vandenbergh. Academic Press, New York.

Vorontsov, N.N., Rhadzabli, S.I. \& Lyapunova, K.L. (1967) Karyological differentiation of allopatric forms of hamsters of the superspecies Phodopus sungorus and heteromorphism of the sex chromosomes in the females. Doklady Akademii Nauk SSSR 172, 703-705.

Wade, G.N. \& Bartness, T.J. (1984) Effects of photoperiod and gonadectomy on food intake, body weight, and body composition in Siberian hamsters. Am. J. Physiol. 246, R26-R30.

Wynne-Edwards, K.E. \& Lisk, R.D. (1984) Djungarian hamsters fail to conceive in the presence of multiple males. Anim. Behav. 32, 626-629.

Wynne-Edwards, K.E., Terranova, P.F. \& Lisk, R.D. (1987) Cyclic Djungarian hamsters, Phodopus campbelli, lack the progesterone surge normally associated with ovulation and behavioral receptivity. Endocrinology 120, (in press).

Yellon, S.M. \& Goldman, B.D. (1984) Photoperiod control of reproductive development in the male Djungarian hamster (Phodopus sungorus). Endocrinology 114, 664-670.

Zeveloff, S.I. \& Boyce, M.S. (1980) Parental investment and mating systems in mammals. Evolution 34, 973-982.

Received 17 September 1986 